\title{
A REESCRITA DE MOÇAMBIQUE EM O ÚLTIMO VOO DO FLAMINGO, DE MIA COUTO
}

\section{THE MOZAMBIQUE REWRITTEN IN THE 0 ÚLTIMO VOO DO FLAMINGO, BY MIA COUTO}

\author{
Thaíse Santana ${ }^{1}$ \\ Sirlei Santos Dudalski
}

\section{RESUMO}

Este artigo apresenta uma análise do romance $O$ último voo do flamingo (2005), do escritor moçambicano Mia Couto. Seu objetivo consiste em reconhecer e apontar, a partir da literatura, algumas especificidades da realidade sociocultural moçambicana no contexto da pós-colonialidade. Para tanto, esta análise se centrará nos sentidos de identidade presentes no romance. Esta investigação tem caráter bibliográfico, com uma proposição metodológica analítico-descritiva, e fundamenta-se, principalmente, no campo dos estudos pós-coloniais. Compreende-se o romance $O$ último voo do flamingo como metáfora da reconstrução de um país que se apresenta devastado pela guerra e pela ganância de seus governantes. Concluímos que a literatura cumpre importante papel ao propiciar a possibilidade de voz àqueles que, de diferentes maneiras, foram silenciados pela história colonial.

PALAVRAS-CHAVE: identidade; romance; literatura moçambicana. 


\section{ABSTRACT}

This article presents an analysis of the novel $O$ último voo do flamingo (2005), by the Mozambican writer Mia Couto. The purpose of the article is to recognize and allude to some specificities of the Mozambican socio-cultural reality in the context of post-coloniality. Therefore, we will analyze the meanings of identity present in the novel. This bibliographic research is based mainly on the field of postcolonial studies It is understood the novel "O último Voo do Flamingo" as a metaphor for the reconstruction of a country that is seen as devastated by the war and the greed of its rulers. We conclude that literature plays an important role in providing the possibility of voice to those who, in different ways, have been silenced by colonial history.

KEYWORDS: identity; novel; Mozambican literature.

\footnotetext{
"Não vê os rios que nunca enchem o mar? A vida de cada um também é assim: está sempre toda por viver". O último voo do flamingo - Mia Couto.
}

O continente africano, com toda sua extensão e pluralidade étnica, linguística, histórica e religiosa é concebido, não raras vezes, como um todo unificado. Essa visão reduzida sustentou-se durante o processo de colonização dos países africanos e dessa história de dominação surgiu uma África inventada pelo ocidente, com história única, definida e contada pela perspectiva eurocêntrica. Desse modo, cenas de destruição, exotismo e miséria são muito recorrentes na composição de certo imaginário ocidental sobre o continente africano. "Essa imagem foi projetada e extrapolada ao infinito ao longo do tempo, passando a justificar tanto o presente quanto o futuro" (Ki-Zerbo, 2010, p. 31).

No livro A invenção da África: gnose, filosofia e ordem do conhecimento, o filósofo congolês Valentin-Yves Mundimbe (2013, p. 10) interroga as construções das imagens ocidentais sobre o continente africano e problematiza o conhecimento imperial e colonial construído por diferentes intelectuais ocidentais. Nesse mesmo sentido, o crítico literário palestino Edward Said expõe essa invenção, referindo-se ao Oriente, o que, por analogia, podemos deslocar para o continente africano. Desse modo, afirmamos que, durante vários séculos, escritores, historiadores, entre outros, utilizaram "não só os trabalhos eruditos, mas também as obras literárias, as passagens políticas, os textos jornalísticos, livros de viagens, estudos religiosos e filológicos" (SAID, 1990, p. 34), isto quer dizer, utilizou-se todo um arsenal literário, no sentido lato da palavra, para descrever e dominar o continente africano. 
São cinco países africanos que têm o português como língua oficial, a saber: Angola, Guiné-Bissau, Moçambique, Cabo Verde e São Tomé e Príncipe. Com exceção dos dois últimos, esses países travaram um longo período de luta armada contra o exército colonial português, a fim de obterem a libertação nacional, e só conquistaram independência na década de 1970. Após a vitória dos movimentos de libertação, afirmou-se nesses países, com suas diferenças e singularidades, literaturas que, entre outros propósitos, celebravam a (re)construção nacional. Desde então, essas literaturas têm sido um importante instrumento para a desconstrução de identidades estereotipadas e para a construção/afirmação de símbolos que produzem sentidos de identificação coletiva aos povos africanos das diferentes nacionalidades.

O romance $O$ último voo do flamingo (2005) é a quinta publicação do gênero na vasta produção literária do escritor Mia Couto. Ele foi publicado, primeiramente, em Portugal, no ano de 2000, na ocasião em que Moçambique completava 25 anos de sua independência. Podemos entendê-lo, desse modo, como a celebração de um país independente, como a reescrita de Moçambique, a partir da literatura. O romance é estruturado em vinte e um capítulos e cada um deles contém uma epígrafe que diz respeito a ditos populares da vila de Tizangara, espaço da narrativa. Há também uma carta do narrador de Tizangara, que pode ser compreendida como o prefácio do romance, um glossário explicativo contendo os termos e expressões referentes às línguas locais, o que, aliás, diz respeito a uma estratégia comum dos escritores africanos para mostrar que, se a língua oficial é portuguesa, a expressão, nesse caso, é moçambicana. Por fim, o romance apresenta a transcrição das palavras de Mia Couto na ocasião em que recebeu o prêmio Mário Antônio, da Fundação Calouste Gulbekian, em 2001, na França, pelo mérito do romance em questão.

O último voo do flamingo (2005) ambienta-se na fictícia e pequena vila de Tizangara, interior de Moçambique, no período posterior às guerras de independência e civil. Nesse contexto, encontram-se os soldados da Organização das Nações Unidas (ONU), responsáveis por acompanhar o processo de paz do país, mas que começam a explodir sem uma explicação, restando-lhes apenas o órgão genital. Acontecimentos insólitos dão o tom do romance em questão, bem como da narrativa coutiana, de modo geral. Para investigar esses acontecimentos, a ONU envia alguns representantes. Entre eles, destaca-se o italiano Massimo Risi. O administrador local, Estêvão Jonas, oferece-lhe um tradutor. Trata-se d'O Tradutor de Tizangara, que é também o narrador da história. Para auxiliar na investigação, convocam a prostituta Ana Deusqueira, para desvendar, a partir do membro genital que sobrou da explosão, a identidade dos mortos.

Nessa trama intrigante, acompanhamos a trajetória de Massimo Risi diante de uma realidade que não condiz com os seus valores eurocêntricos, causando-lhe estranhamento e perturbação, a princípio, mas que depois muda de perspectiva ao se apaixonar pela misteriosa Temporina - mu- 
lher com o rosto de velha no corpo de uma jovem exuberante. Durante o desenvolvimento da narrativa, alguns personagens apresentam suas versões dos fatos, na tentativa de elucidarem as mortes dos soldados. Dessa forma, cria-se um suspense que é desvendado somente no final do romance.

Ao longo da narrativa, Mia Couto tece algumas críticas, sobretudo aos descaminhos tomados por alguns militantes que tinham posicionamento político à esquerda, como é o caso do personagem do administrador Estêvão Jonas. Ele é ex-guerrilheiro revolucionário da Frente para a Libertação de Moçambique (FRELIMO), que lutou contra o exército colonial português no período de guerra pela independência. Contudo, no contexto de um país independente, ele empreende um jogo de poder pautado no favorecimento próprio e na indiferença ao povo moçambicano.

O romance também ilustra a invisibilidade conferida aos povos africanos de um modo geral, pois as mortes por explosão em Moçambique só preocupam a comunidade internacional quando cinco soldados da ONU são as vítimas. Mia Couto, a partir do seu romance, denuncia um sério problema do país no pós-guerra: as minas subterrâneas, as quais mataram e mutilaram muitos moçambicanos, situação possível de ser compreendida como um prolongamento da guerra, ainda que oficialmente ela tenha terminado. No entanto, apesar do romance tematizar a problemática da guerra em Moçambique, ele apresenta uma narrativa marcadamente poética, o que nos remete ao pensamento de Antônio Candido:

Assim como os médicos e farmacêuticos misturam açúcar num remédio amargo mas necessário, ou pintam da cor do ouro uma pílula de gosto repelente, para levarem as crianças a ingeri-los em seu próprio benefício, a verdade crua e por vezes dura pode ser disfarçada com os encantos da fantasia, para chegar melhor aos espíritos (CANDIDO, 1989, p. 84).

É com o encantamento da palavra que Mia Couto narra as problemáticas de um país que sofreu um processo de colonização e sofre os seus efeitos na contemporaneidade. Entendemos que "o colonialismo gira em torno de um pressuposto no qual o poderoso centro cria a sua periferia. Embora o binômio centro/margem seja uma noção binária, ela define o que ocorreu na representação dos indivíduos durante o período colonial" (Bonnici, 2009, p. 264) ${ }^{3}$. De acordo com o historiador e cientista político camaronês Achille Mbembe (2017, p. 38), a colonização configura-se como o principal motor do regime de desigualdades à escala planetária. Fazemos tal declaração no tempo presente, seguindo o pensamento de Mbembe (2017), e por entendermos que o fim das administrações coloniais não determinou o fim do colonialismo. Embora as antigas colônias tenham conquistado o patamar de Estados-nação, não vivemos num mundo descolonizado, porque a estrutura das relações centro-periferia não se transformou significativamente. 
Tendo em conta estes pressupostos, ressaltamos que as análises desenvolvidas neste artigo estão pautadas na teoria e crítica pós-colonialistas, que, de acordo com Thomas Bonnici, "abrange a cultura e a literatura, ocupando-se de perscrutá-las durante e após a dominação imperial europeia, de modo a desnudar seus efeitos sobre as literaturas contemporâneas" (BONNICI, 2009, p. 267). Adotando uma perspectiva crítica em relação a tais estudos, vale notar que eles foram estabelecidos nos centros de saber, por pensadores provenientes de ex-impérios colonialistas, mas não se pode negar que promoveram mudanças "no campo dos estudos culturais (e literários), [pois permitiram] a análise das relações de poder, nas diversas áreas da atividade social caracterizada pela diferença: étnica, de raça, de classe, de gênero, de orientação sexual" (MATA, 2014, p. 1). Desse modo, os estudos pós-coloniais possibilitaram a abertura de novos espaços para os povos que foram colonizados, desafiando, dessa forma, "as narrativas legitimadoras anteriores" (HAMILTON, 1999, p. 14).

O romance $O$ último voo do flamingo (2005) desnuda essas dominações e reescreve o país Moçambique, a partir de uma perspectiva interna. A construção de identidades no romance em questão passa pela afirmação de elementos culturais que dizem respeito à língua, costumes, entre outras manifestações culturais próprias às pessoas da vila de Tizangara, que podemos compreender como manifestações culturais moçambicanas. De acordo com Stuart Hall:

[...] no mundo moderno, as culturas nacionais em que nascemos se constituem em uma das principais fontes de identidade cultural. Ao nos definirmos, algumas vezes dizemos que somos ingleses ou galeses ou indianos ou jamaicanos. Obviamente, ao fazer isso estamos falando de forma metafórica. Essas identidades não estão literalmente impressas em nossos genes. Entretanto, nós efetivamente pensamos nelas como se fossem parte de nossa natureza essencial (HALL, 2006, p. 47).

Stuart Hall aponta que a identidade cultural deve ser compreendida, sempre, como uma construção histórica. No caso de Moçambique, a oralidade é um dos elementos que constituem uma identidade moçambicana. De acordo com Laura Padilha, "a arte milenar da oralidade difunde vozes ancestrais, procura manter a lei do grupo, fazendo-se, por isso, um exercício de sabedoria" (PADILHA, 2007, p. 35). Mia Couto utiliza muitas histórias que os seus conterrâneos lhe contam para tecer as suas narrativas. Já nas primeiras páginas do romance em questão, tem-se uma dedicatória à Joana Tembe e ao João Joãoquinho que, segundo o escritor, lhe "contaram estórias como quem rezava" (COUTO, 2005, p. 05). Podemos entender muitas histórias da vila de Tizangara como também histórias de Moçambique.

No primeiro capítulo do romance somos apresentados ao mistério que envolve a trama, como mostra a passagem que segue: 
$\mathrm{Nu}$ e cru, eis o facto: apareceu um pénis decepado, em plena Estrada Nacional, à entrada da vila de Tizangara. Era um sexo avulso e avultado. Os habitantes relampejaram-se em face do achado. Vieram todos, de todo lado. Uma roda de gente se engordou em redor da coisa. Também eu me cheguei, parado nas fileiras mais traseiras, mais posto que exposto. Avisado estou: atrás é onde melhor se vê e menos se é visto. Certo é o ditado: se a agulha cai no poço muitos espreitam, mas poucos descem a buscá-la. Na nossa vila, acontecimento era coisa que nunca sucedia. Em Tizangara só os factos são sobrenaturais. E contra factos tudo são argumentos. Por isso, tudo acorreu, ninguém arredou. E foi o inteiro dia, uma roda curiosa, cozinhando rumores. Vocabuliam-se dúvidas, instantaneavam-se ordens (COUTO, 2005, p. 10) ${ }^{4}$.

Nesse trecho citado, o narrador apresenta-nos o fato insólito que evidencia as mortes explosivas dos soldados da ONU. É importante notar a forma como Mia Couto costura a sua narrativa. Nos trechos destacados em negrito, notamos que ele utiliza palavras já conhecidas do nosso português e reconfigura seus usos e sentidos, operando, assim, um movimento de renovação no léxico. Sabemos que a criação desses neologismos é característica da estética do referido escritor, a qual confere a sua narrativa um caráter peculiar. Como podemos perceber, "a obra literária de Mia Couto é escrita em português, mas os ruídos que dela brotam deslocam a língua européia, alocam construções que a subvertem e estimulam uma transgressão escancarada" (FONSECA, 2008, p. 88).

Notamos, desde o título, e mais adiante, que o flamingo é um símbolo central no romance. Sua figura tem importância na construção da narrativa, como também no imaginário do povo de Tizangara. Vejamos a seguir o relato do narrador:

Em fins de tarde, os flamingos cruzavam o céu. Minha mãe ficava calada, contemplando o voo. Enquanto não se extinguissem os longos pássaros ela não pronunciava palavra. Nem eu me podia mexer. Tudo, nesse momento, era sagrado. Já no desfalecer da luz minha mãe entoava, quase em surdina, uma canção que ela tirara de seu invento. Para ela, os flamingos eram eles que empurravam o sol para que o dia chegasse ao outro lado do mundo (COUTO, 2005, p. 47).

Percebemos no trecho acima que os flamingos compõem o imaginário da mãe do narrador, e do povo de Tizangara, de modo geral. Na percepção do narrador, os flamingos são os responsáveis por fazerem o sol brilhar do outro lado do mundo. A presença dessas figuras no romance quase sempre está relacionada a um sentido que escapa ao nosso entendimento. Mais adiante, notamos também que a aparição de um inseto no quarto da pousada onde Masimo Risi estava hospedado não representa um episódio comum. De acordo com o Tradutor de Tizangara "um louva-a-deus não era um simples insecto. Era um antepassado visitando os viventes. Expliquei a crença a Massimo: aquele bicho andava ali em serviço de 
defunto. Matá-lo podia ser um mal prenúncio" (COUTO, 2005, p. 60). Risi fica ainda mais espantado quando o recepcionista informa que o inseto morto era Hortênsia, a tia de Temporina. O italiano, a essa altura, ainda não conseguiria entender que, na vila de Tizangara, o mundo dos vivos e dos mortos estão interligados. Para ele, o problema da língua é menor diante desses acontecimentos, e acrescenta: "o que eu não entendo é esse mundo daqui" (COUTO, 2005, p. 40). Essa afirmação do personagem demonstra que a sua vivência eurocêntrica explica a incompreensão diante desse mundo outro, diferente do seu. Entendemos que a ocorrência desses elementos na ficção coutiana opera como expressão das tradições. Ademais, "grande parte das narrativas de Mia Couto utiliza o insólito como meio de criticar o real opressor e de subverter os cânones da racionalidade européia" (SECCO, 2006, p. 2).

Estão também presentes no romance os aspectos religiosos ligados à cultura moçambicana, como demonstra a passagem a seguir:

Minha esposa, a ex-camarada Ermelinda, também não me ajuda. Ela adora os poderes e as riquezas, mas recebe as más influências. Às vezes, ela frequenta as missas pouco católicas desse padre Muhando. Mesmo desconfio que ela visita-se lá no feiticeiro, o tal Zeca Andorinho (COUTO, 2005, p. 95).

Notamos no trecho destacado que o administrador Estêvão Jonas não concorda com o diálogo que o padre Muhando estabelece com as religiões do lugar. Ademais, ele discrimina as religiões dos povos africanos dizendo serem más influências para a sua mulher. Essa demonstração ilustra o embate entre as crenças religiosas. Vale ressaltar que ele é um homem negro, inclusive se declara como tal, mas revela que os seus conterrâneos não são da sua raça. Em seguida, ele admite: "pode ser que eu seja um racista étnico" (COUTO, 2005, p. 95). Percebemos também a problemática do racismo nessa faceta diversificada, pois o administrador, um homem que se declara negro, mas que por seu status social julga ser melhor que as outras pessoas da sua raça.

Há também denúncias ao racismo, feitas a partir da voz conferida à personagem Hortênsia: "quer saber por que fiquei sempre na varanda? Para ver se Deus me escolhia e me levava. Nunca me levou. Eu sou muito negra, deve ser por causa disso que, mesmo eu ficando frente à igreja, ele nunca me escolheu" (COUTO, 2005, p. 65). Essa problemática coaduna com o pensamento de Stuart Hall, quando afirma que:

[...] o movimento que vai da colonização aos tempos pós-coloniais não implica que os problemas do colonialismo foram resolvidos ou sucedidos por uma época livre de conflitos. Ao contrário, o "pós-colonial" marca a passagem de uma configuração ou conjuntura histórica de poder a outra (Hall, 1996a). Problemas de dependência, subdesenvolvimento e marginalização, típicos do "alto" período colonial, persistem no pós-colonial. Contudo, essas relações estão resumidas em uma nova configuração (HALL, 2013, p. 62)5. 
Esse pensamento converge com os pressupostos de Achille Mbembe (2013, p. 38) sobre as desigualdades produzidas pela colonização, como já expomos anteriormente. Nessa citação do romance percebemos que o racismo, ainda que possua origem mais antiga, seguindo Carlos Moore $(2007)^{6}$, foi disseminado pelos brancos europeus durante o processo de colonização, se reconfigurou e permeia as relações dos indivíduos num Moçambique já pós-colonial. De acordo com Frantz Fanon (2011, p. 274), "o racismo não pode esclerosar-se. Teve de se renovar, de se matizar, de mudar de fisionomia. Teve de sofrer a sorte do conjunto cultural que o informava" para continuar estruturando as instituições e as relações dos indivíduos.

$\mathrm{Na}$ passagem que destacamos a seguir, na qual Temporina dá orientações a Massimo Risi sobre como fugir das minas explosivas, compreendemos que essas recomendações vão mais além. Temporina parece ensinar a Massimo Rissi como ele deve se portar no seu mundo:

Andei olhando para você. Desculpa, Massimo, mas você não sabe andar: - Como não sei andar? - Não sabe pisar. Não sabe andar neste chão. Venha aqui: lhe vou ensinar a caminhar. - Ele riu, acreditando ser brincadeira. Porém, ela grave, advertiu: - Falo sério: saber pisar neste chão é assunto de vida ou morte. Venha que eu lhe ensino. O italiano cedeu. Aproximaram-se e sustiveram-se mãos nas mãos. Parecia que dançavam, o italiano aliviando o seu peso à medida que o seu pé se afeiçoava ao chão (COUTO, 2005, p. 68).

Percebemos, nesse trecho, a entrega do italiano e a cumplicidade do casal. Mais adiante, "Temporina o ia encorajando: pise como quem ama, pise como se fosse sobre um peito de uma mulher. E o conduzia de encosto e gesto" (COUTO, 2005, p. 68). A terra, por sua vez, parece dar-lhe uma resposta positiva. Numa ocasião em que Massimo se encontra sobre minas subterrâneas, esses ensinamentos salvam a sua vida, como demonstra a passagem que segue: "[Massimo] começou a caminhar. Vagaroso, todo o corpo era um calcanhar [...] Massimo Risi passou pelo terreno minado como Jesus se deslocou sobre as águas" (COUTO, 2005, p. 200).

$\mathrm{Na}$ cena em que o narrador de Tizangara encontra-se na floresta para fugir das explosões, ele percebe a presença de sua falecida mãe e a pede que lhe conte a história dos flamingos. Numa descrição em tom poético, a voz da mulher ecoa na narrativa:

Havia um lugar onde o tempo não tinha inventado a noite. Era sempre dia. Até que, certa vez, o flamingo disse: - Hoje farei meu último voo! As aves, desavisadas, murcharam. Tristes, contudo, não choraram. Tristeza de pássaro não inventou lágrima. Dizem: lágrima dos pássaros se guarda lá onde fica a chuva que nunca cai. Ao aviso do flamingo, todas as aves se juntaram. Haveria uma assembleia para se conversar o assunto. Enquanto o flamingo não chegava, se escutavam os pios em rodopios [...] O pernalta, enfim, chegou e expli- 
cou - que havia dois céus, um de cá, voável, e um outro, o céu das estrelas, inviável para voação. Ele queria passar essa fronteira [...] - Me cansei de viver num só corpo. E falou. Queria ir lá para onde não há sombra, nem mapa. Lá onde tudo é luz. Mas nunca chega a ser dia. Nesse outro mundo ele iria dormir como um deserto, esquecer que sabia voar, ignorar a arte de pousar sobre a terra. - Não quero posar mais. Só repousar. E olhou por cima. O céu parecia baixo, rasteiro. $\mathrm{O}$ azul desse céu era tão intenso que se vertia líquido, nos olhos dos bichos. Então, o flamingo se lançou, arco e flecha se crisparam em seu corpo. E ei-lo, eleito, elegante, se despindo do peso. Assim, visto em voo, dir-se-ia que o céu se vertebrara e a nuvem, adiante, não era senão alma de passarinho. Dir-se-ia mais: que era a própria luz que voava. E o pássaro ia desfolhando, asa em asa, as transparentes páginas do céu. Mais um bater de plumas e, de repente, a todos pareceu que o horizonte se vermelhava. Transitava de azul para tons escuros, roxos e liláceos. Tudo se passando como um incêndio. Nascia, assim, o primeiro poente. Quando o flamingo se extinguiu, a noite se estreou naquela terra. Era o ponto final (COUTO, 2005, p. 113-4).

Compreender a simbologia do flamingo ilustrada acima é fundamental para o entendimento da narrativa, mas não só, pois, na tradição moçambicana, "os flamingos são os eternos anunciadores de esperança" (COUTO, 2005, p. 223). Ana Mafalda Leite explica:

As aves, consideradas a personificação do ar, têm a leveza de todas as imagens aéreas que simbolizam, essencialmente, a desmaterialização e a libertação da alma, o sonho e o espírito, transcendência da condição humana, viagem onírica do voo. Enquanto mediadoras entre terra e céu, as aves e o simbolismo das suas asas, que se aliam ao levantar do voo, permitem, também, pela vertigem em ascensão, a experiência do sublime (LEITE, 2003, p. 36).

Depois que a voz da mulher se desvaneceu, o Tradutor de Tizangara olhou o poente e viu "as aves carregando o sol, empurrando o dia para outros aléns” (COUTO, 2005, p. 115). Aquela era a sua última noite na floresta, na manhã seguinte, ele "já entrava na vila, como quem regressa a seu próprio corpo depois do sono" (COUTO, 2005, p. 115). No dia seguinte, novas explosões acontecem na vila da Tizangara, até que, por fim, a terra transforma-se em um imenso abismo. Segundo Suplício, pai do narrador de Tizangara:

Já acontecera com outras terras de África. Entregara-se o destino dessas nações a ambiciosos que governaram como hiena, pensando apenas em engordar rápido. Contra esses desgovernantes se tinha rezou-se aos santos. Tudo fora em vão: não havia melhora para aqueles países. Faltava gente que amasse a terra. Faltavam homens que pusessem respeito nos outros homens. Vendo que a solução não havia, os deuses experimentado o inatentável: ossinhos mágicos, sangue 
de cabrito, fumos de presságio. Beijaram-se as pedras, decidiram transportar aqueles países para esses céus que ficam no fundo da terra [...] Nesse lugar onde nunca nada fizera sombra, cada país ficaria em suspenso, à espera de um tempo favorável para regressar ao seu próprio chão (COUTO, 2005, p. 216).

Nessa passagem que destacamos, Suplício explica a causa do desaparecimento da terra. Entretanto, tal explicação não tem um fundamento racional, o que abala ainda mais as crenças de Massimo Risi. Outro acontecimento insólito aparece na cena: uma canoa com os ossos que Suplício havia retirado do seu corpo, como faz de costume, para que os seus ossos descansem. Contudo, antes de partir, ele pede ao filho: "Fica, já disse. Para contar aos outros o que aconteceu com nosso mundo. Não quero que seja esse, de fora a falar desta nossa história” (Couto, 2005, p. 218). O velho refere-se a Massimo Risi, pois acredita que os brancos europeus não são confiáveis. Ademais, ele entende que os relatos sobre os acontecimentos do seu lugar devem ser feitos por uma voz local, nesse caso, pelo tradutor oficial da vila de Tizangara, que é também o narrador do romance. De acordo com Isaías Carvalho (2009):

A experiência pessoal do narrador principal [...] faz com que lhe seja delegada a tarefa da doação de voz aos silenciados da História (com H maiúsculo). Trata-se de um narrador que diz Nós, ou uma multiplicidade de narradores, numa polifonia em que as vozes anônimas da coletividade encontram um meio possível e produtivo de expressão (CARVALHO, 2009, p. 8).

Seguindo a perspectiva de Carvalho (2009), podemos caracterizar o Tradutor de Tizangara como um narrador pós-colonial, que, diferentemente do narrador pós-moderno de Silviano Santiago (2002), narra a trama como um personagem atuante. Parafraseando Carvalho (2009), o caráter relacional e coletivo desse narrador de Tizangara lhe é central na narrativa pós-colonial moçambicana. De acordo com Mia Couto, em debate na Bienal do Livro do Rio de Janeiro (2013), a África deve contar a sua própria história dando voz a toda a sua diversidade interna e afastando-se da visão homogeneizante e eurocêntrica ainda presente.

Ao final da narrativa, a canoa onde estavam o Tradutor de Tizangara e Massimo Risi foi afastando-se. De acordo com o narrador, ela "pareceu ser não um barco, mas um pássaro. Um flamingo que se afastava, pelos aléns. Até tudo ser neblina, tudo nuveado" (COUTO, 2005, p. 219). Massimo Risi, por sua vez, preocupa-se apenas em escrever seu relatório para explicar aos seus superiores o motivo do desaparecimento da vila de Tizangara. Mais adiante, num tom de desabafo, o italiano escreve:

Cumpre-me o doloroso dever de reportar o desaparecimento total de um país em estranhas e pouco explicáveis circunstâncias. Tenho consciência que o presente relatório conduzirá à minha demissão dos quadros de consultores da 
ONU, mas não tenho alternativa senão relatar a realidade com que confronto: que todo este imenso país se eclipsou, como que por golpe de magia. Não há território, nem gente, o próprio chão se evaporou num imenso abismo. Escrevo na margem desse mundo, junto do último sobrevivente dessa nação (COUTO, 2005, p. 219).

À beira do abismo, restam apenas o tradutor de Tizangara e Massimo Risi. Este transforma em pássaro de papel a folha que escreveu seu relatório para as Nações Unidas e lança-o fora. O pássaro plana no ar, enquanto eles ficam à espera de outro flamingo. Nas últimas cenas do romance é revelado o mistério sobre as mortes dos soldados da ONU e dos outros moçambicanos. Na realidade, essas mortes são de responsabilidade do administrador e seu enteado, os quais recebiam verba para financiar o projeto de desarmamento das minas subterrâneas, mas nada faziam. Dessa forma, moçambicanos continuavam a morrer, enquanto o administrador recebia mais dinheiro para o referido projeto, empreendendo, assim, um jogo inescrupuloso. Nas palavras de Mia Couto:

O último voo do flamingo fala de uma perversa fabricação de ausência - a falta de uma terra toda inteira, um imenso rapto de esperança praticado pela ganância dos poderosos. $\mathrm{O}$ avanço desses comedores de nações obriga-nos a nós, escritores, a um crescente empenho moral. Contra a indecência dos que enriquecem à custa de tudo e de todos, contra os que têm as mãos manchadas de sangue, contra a mentira, o crime e o medo, contra tudo isso se deve erguer apalavra dos escritores (COUTO, 2005, p. 224).

Podemos compreender $O$ último voo do flamingo como metáfora da reconstrução de um país que se apresenta devastado pela guerra e pela ganância de seus governantes. Nesse romance, Mia Couto impregna sua narração com elementos próprios da cultura local e a dissemina ao longo das páginas do livro. O escritor expõe os acontecimentos históricos do seu país, como a problemática da guerra, e tece críticas àqueles que semeiam e se beneficiam da miséria que ela provoca. Por outro lado, a sua narrativa demonstra esperança na reconstrução de um novo Moçambique, como já anuncia a epígrafe deste artigo, mas não se trata de uma esperança ingênua. Nas palavras de Mia Couto, seu compromisso com a escrita sobre sua terra e o seu tempo guiou "não apenas este livro como os romances anteriores. Em todos eles me confrontei com os mesmos demónios e entendi inventar o mesmo território de afecto, onde seja possível refazer crenças e reparar o rasgão do luto em nossas vidas" (COUTO, 2005, p. 224). De fato, o papel do intelectual consiste em "criticar os poderes constituídos e autorizados da nossa sociedade, que são responsáveis pelos seus cidadãos, particularmente quando esses poderes são exercidos numa guerra manifestamente desproporcional e imoral” (SAID, 2005, p. 100). 


\section{REFERÊNCIAS BIBLIOGRÁFICAS}

BONNICI, Thomas; ZOLIN, Lucia Osana (Org). Teoria Literária: Abordagens históricas e tendências contemporâneas. 3. ed. rev. e ampl. Maringá: Eduem, 2009.

CANDIDO, Antonio. O patriarca. In: A educação pela noite e outros ensaios. 2. ed. São Paulo: Ática, 1989.

CARVALHO, Isaías Francisco de. O narrador pós-colonial. In: Anais I CONLIRE. Ilhéus: UESC, 2009.

COUTO, Mia. O último voo do flamingo. São Paulo: Companhia das Letras, 2005.

COUTO, Mia. O que é um autor? Agruras e prazeres de quem se dedica à escrita. Debate no espaço Café Literário durante a $16^{a}$ Bienal do livro do Rio. Rio de Janeiro, RJ, 01/09/13. Disponível em: <http://globotv.globo. $\mathrm{com} /$ globocom/g1/v/veja-o-debate-na-bienal-o-que-e-um-autor-agruras-e-prazeres-de-quem-se-dedica-a-escrita/2858614>. Acesso em: jul. 2013.

FANON, Frantz. Racismo e cultura. In: SANCHES, M. R. (Org). Malhas que os impérios tecem. Textos anticoloniais, contextos pós-coloniais. Lisboa: Edições 70, 2011.

FONSECA, Maria Nazareth Soares. Literaturas africanas de língua portuguesa: percursos da memória e outros trânsitos. Belo Horizonte: Veredas de cenários, 2008.

HALL, Stuart. A identidade cultural na pós-modernidade. Tradução de Tomaz Tadeu da Silva, Guaracira Lopes Louro. 11. ed. Rio de Janeiro: DPßA, 2006.

HALL, Stuart. Da Diáspora: Identidades e Mediações Culturais. Liv Sovik (org); Tradução de Adelaine La Guardia Resende. 2. ed. Belo Horizonte: Editora UFMG, 2013.

HAMILTON, Russel. A literatura dos PALOP e a teoria pós-colonial. São Paulo: Departamento de Letras Clássicas e Vernáculas/FFLCH/USP, 1999, v. 3, p.12-23, Col. Via Atlântica.

KI-ZERBO, Joseph. História geral da África: metodologia e pré-história da África.

2. ed. Brasília: Unesco, 2010. Disponível em: <http://www.dominiopublico.gov.br/download/texto/ue000318.pdf.>. Acesso em: fev. 2018.

LEITE, Ana Mafalda. Literaturas Africanas e Formulações Pós-Coloniais. Lisboa: Edições Colibri, 2003.

MATA, Inocência. Estudos pós-coloniais. Desconstruindo genealogias eurocêntricas. Civitas - Revista de Ciências Sociais, vol. 14, núm. 1, 
jan-abril, 2014, pp. 27-42 Pontifícia Universidade Católica do Rio Grande do Sul Porto Alegre, Brasil. Disponível em: http://www.redalyc.org/articulo.oa? id=74230601003\%

MBEMBE, Achille. Políticas da inimizade. Trad. Marta lança. Lisboa: Antígona, 2017.

MOORE, Carlos. Racismo e sociedade: novas bases epistemológicas para entender o racismo. Belo Horizonte: Mazza Edições, 2007.

MUDIMBE, Valentin-Yves. A invenção de África: Gnose, filosofia e a ordem do conhecimento. Mangualde (Portugal), Luanda: Edições Pedago; Edições Mulemba, 2013.

PADILHA, Laura. Entre voz e letra: o lugar da ancestralidade na ficção angolana do século XX. Niteroi: EdUFF, 1995.

SAID, Edward. Orientalismo: o Oriente como invenção do Ocidente. Tradução de Tomás Rosa Bueno. 1. reimp. São Paulo: Companhia das Letras, 1990.

SAID, Edward. Representações do intelectual: as Conferências Reith de 1993. Tradução de Milton Hatoum. São Paulo: Companhia das Letras, 2005.

SECCO, Carmen Lúcia Tindó Ribeiro. Mia Couto: o outro lado das palavras e dos sonhos. Via Atlântica, São Paulo, v. 9, n. 1, p. 71-84, 2006. Disponível em http://www.revistas.usp.br/viaatlantica/article/view/50041

Recebido para publicação em 31/05/2018

Aprovado em 04/08/2018

\section{NOTAS}

1 Mestranda em Estudos Literários na Universidade Federal de Viçosa. Bolsista Capes. Pesquisadora do Grupo Literatura, História e Cultura: encruzilhadas epistemológicas (CNPq/UESC).

2 Professora Dra. de Literatura nos cursos de Graduação e Mestrado da Universidade Federal de Viçosa.

3 Grifos do autor.

4 Grifos nossos.

5 Grifos do autor.

6 Carlos Moore, em seu livro Racismo e sociedade: novas bases epistemológicas para a compreensão do racismo na história (2007) descortina a gênese do racismo. Ciente sobre a origem africana de todas as populações humanas e o povoamento do planeta a partir desse continente, ele constata, a partir dos trabalhos do antropólogo espanhol Gervásio Fournier-González (1901) e do antropólogo senegalês Cheikh Anta Diop (1974; 1991), que "a hostilidade e o medo da cor especificamente negra é um fenômeno francamente universal que se encontra nos mitos e nas culturas de praticamente todos os povos não-negros" (MOORE, 2007, p. 49-50). Ele afirma que essa constatação é facilmente verificável a partir do exame dos mitos arquetípicos dos povos euro-semitas da Europa e do Oriente Médio, com destaque para o Rig-Veda, o livro mais antigo da trilogia de livros sagrados indianos, composto entre 1000 e 500 a.C. 